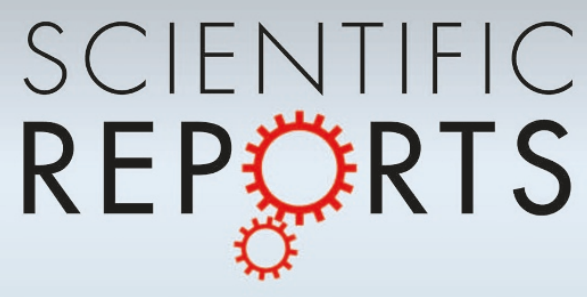

OPEN

SUBJECT AREAS:

BIODIVERSITY

COMPUTATIONAL BIOLOGY AND BIOINFORMATICS

ZOOLOGY

ANIMAL BEHAVIOUR

Received

6 June 2012

Accepted

1 October 2012

Published

18 October 2012

Correspondence and requests for materials should be addressed to A.M. (antoni. margalida@iee.unibe.

ch)

\title{
Modelling the effects of sanitary policies on European vulture conservation
}

\author{
Antoni Margalida ${ }^{1} \& M^{a}$ Àngels Colomer ${ }^{2}$
}

'Division of Conservation Biology, Institute of Ecology and Evolution, University of Bern, Baltzerstrasse, 6, 3012, Bern, Switzerland,
2Department of Mathematics, University of Lleida, Av. Alcalde Rovira Roure, 191, 25198, Lleida, Spain.

Biodiversity losses are increasing as a consequence of negative anthropogenic effects on ecosystem dynamics. However, the magnitude and complexity of these effects may still be greatly underestimated. Most Old World vultures have experienced rapid population declines in recent years. In Europe, their immediate conservation depends on changes in health regulations affecting the availability of food provided by domestic carcasses. Information is lacking on the effects of a hypothetical food shortage on the population dynamics of vultures, and is necessary to assess the potential impacts of policy decisions on future changes in biodiversity and ecosystem services. A novel computational model (P-systems) was used to model these effects, forecasting a rapid decline in the Eurasian griffon vulture (Gyps fulvus). By contrast, vulture species with greater plasticity in their dietary range appeared less sensitive to declining food availability. This study extends our understanding of vulture ecosystem services, which have social and economic implications.

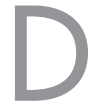

uring the last decade, the relationship between biodiversity and ecosystem function has emerged as an important issue due to the strong connection between the ecological mechanisms that maintain biodiversity in a community and their ecological consequences for ecosystem function ${ }^{1-3}$. However, few ecosystem service assessment approaches have direct utility in political, social and ecological decision-making. Ecosystem services are natural processes that benefit humans, with birds contributing to four of the service types (provisioning, regulating, cultural, and supporting services) recognised by the UN Millennium Ecosystem Assessment ${ }^{4-6}$.

Avian scavengers are part of the detrital food web of ecosystems and they provide the important ecological service of recycling carrion biomass to prevent the accumulation of dead biomass, thereby contributing to waste removal, disease regulation, and nutrient cycling?.

At the start of the 21st century, European avian scavenger communities were one of the few exceptions to the global decline in Old World avian scavenger birds ${ }^{8-12}$. Asian and, to a lesser degree African, vulture populations declined as a consequence of ingestion of veterinary drugs and due to illegal poisoning ${ }^{8-12}$. On the contrary, European vulture populations maintained or increased their numbers ${ }^{13}$. However, the detection of variant (vCJD) and new variant (nvCJD) Creutzfeldt-Jakob disease in humans, which was acquired from cattle infected by bovine spongiform encephalopathy (BSE), led to sanitary legislation (Regulation CE 1774/2002) that greatly restricted the use of animal by-products that were not intended for human consumption. Thus, all carcasses of domestic animals had to be collected from farms and transformed or destroyed in authorised plants, although only $80 \%$ of domestic carcasses are currently recovered by specialised companies ${ }^{13}$. In Spain, since 2006 supplementary feeding points for vultures, supplied by intensive farming, have also greatly diminished $(-80 \%)$ as a consequence of sanitary regulations ${ }^{14}$. The disparity between sanitary and environmental policies, i.e., to eliminate corpses versus to conserve scavenger species ${ }^{3,15,16}$, led to several European dispositions that regulated the use of animal byproducts as food for necrophagous birds ${ }^{13,16}$. Revised regulations on the use of animal by-products that are not intended for human consumption were made by the end of 2011 and they will be applied during $2012^{17}$. However, there has been no assessment of food availability or of the effects of different trophic scenarios on the population dynamics of European vultures. Recently, as a consequence of food shortages, several demographic warning signals have been documented, including a halt in population growth, decreased breeding success, and an apparent increase in mortality among younger age classes ${ }^{18}$. However, empirical analyses of the relationships between vulture population dynamics and food availability have only assessed the role of wild ungulates ${ }^{19}$. Modelling the effects of sanitary laws on population trends may provide evidence that can inform the design of policies that are compatible with vulture conservation. Multi-agent models are necessary for modelling population dynamics relative to demographic parameters and food availability ${ }^{20}$ such as $\mathrm{P}$ Systems, which is a 

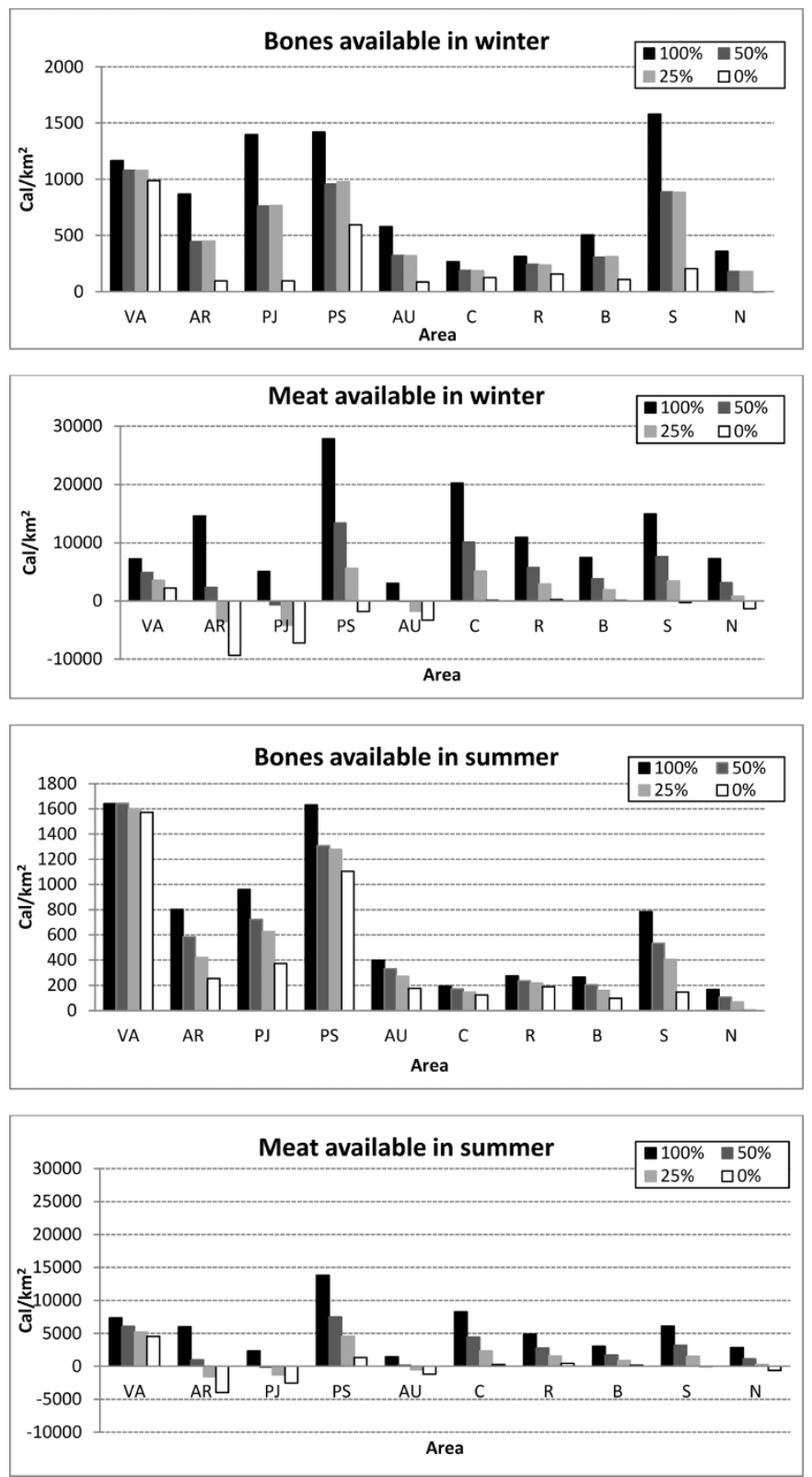

Figure $1 \mid$ Spatial and temporal estimate of the difference between the biomass estimated by the model and the energetic requirements for the current avian scavenger population standardized by surface unit (expressed in calories per $\mathrm{km}^{2}$ ) in the ecosystem, for each of 10 municipalities in Catalonia, Northern Spain, according to the four scenarios of food availability considered $(100 \%, 50 \%, 25 \%$ and $0 \%$ of food provided by domestic ungulates).

computational modelling paradigm that was inspired by the functioning of cells working in parallel ${ }^{21,22}$. This technique was applied recently in several approaches to modelling the dynamics of scavenger species ${ }^{19,23,24}$. However, these studies did not consider future trends in vulture populations under different trophic scenarios. They also failed to take into account the temporal distribution of feeding resources in different breeding seasons (i.e., winter vs. summer) ${ }^{25}$ and the spatial scale of areas where the resources were homogenously distributed. This theoretical approach is valid, but the results obtained are limited from an ecological viewpoint because the models failed to detect spatial changes in species distributions or temporal limitations in food availability. Managers and conservationists require more detailed data to accurately determine parameters for optimising investment in the management of resources. These parameters include the carrying capacity, suitable areas with potential for recolonisation, or the benefits of supplying supplementary feeding sites.

The present study used $\mathrm{P}$ systems to test the effects of variable levels of food availability over 21 years, on the population viability and conservation of four European vultures (the Eurasian griffon vulture Gyps fulvus, the Egyptian vulture Neophron percnopterus and the cinereous vulture Aegypius monachus considered as meateaters and the bearded vulture Gypaetus barbatus, considered a specialized bone-eater) as a consequence of sanitary regulations (see Methods). Taking into account a well-studied region in northern Spain (with 10 subareas) inhabited by the four European vulture species, we model the effects of available domestic carcasses (testing four initial scenarios of $100 \%, 50 \%, 25 \%$, and $0 \%$ of domestic carcasses available in the field and separating meat and bone remains available as a consequence of the different dietary habits between meat and bone consumers) on their population dynamics. The $100 \%$ scenario represents conditions before the outbreak of BSE $(<2002)$ while the $0 \%-25 \%$ scenarios represent the current conditions, depending on the area considered, as food limitations progressively worsened between 2006 and 2012. Future changes to the sanitary legislation may modify the availability of domestic carcasses and will probably progressively increase food availability, shifting conditions from $0-25 \%$ to $50 \%$ and expected to ultimately reach pre-outbreak conditions ( $100 \%$ of domestic carcasses available).

Spain contains the most important European vulture populations (approximately 95\% of their total numbers) and the results may have particularly important conservation applications in the assessment of their ecosystem services, the function of supplementary feeding sites, the carrying capacity, or the feeding resources available in an ecosystem during future reintroduction projects. The hypothetical effects of sanitary restrictions on vulture conservation were estimated and this method provides a computational tool that could be applied in other countries.

\section{Results}

Temporal and spatial food availability in different management scenarios. Meat was predicted to be the major factor limiting the survival of avian scavengers during winter and summer (Figure 1). In the breeding season (winter), the available food was predicted to be insufficient to cover energetic requirements in two areas with half the domestic carcasses available (PJ and AU), which increased to three (also AR) with a quarter of the domestic carrion available (current situation) and six (also PJ, N and S) without domestic carcasses available (with insufficient bone biomass in $\mathrm{N}$ ). In the summer scenario, food availability was predicted to be higher due to transhumance. However, the food available was also predicted to be insufficient in one area (PJ) with half the domestic carcasses, increasing to three areas (also $\mathrm{AR}$ and $\mathrm{AU}$ ) with a quarter of the domestic carrion available to vultures and five (also $\mathrm{N}$ and $\mathrm{S}$ ) without domestic carcasses. From a population perspective, these three areas (AR, PJ and AU) were the most important for the avian scavenger guild because the areas with a quarter of the domestic carcasses available contain $59 \%$ of the bearded vulture population, $56 \%$ of Egyptian vultures, $71 \%$ of griffon vultures, and $100 \%$ of cinereous vultures in the study area.

Population dynamics in different management scenarios. The population trends of bearded, Egyptian and cinereous vultures were predicted to increase in relation to the current situation and were similar across the four scenarios considered (bearded vulture: $\mathrm{F}_{3,83}=$ 2.61, $\mathrm{P}=0.057$; Egyptian vulture: $\mathrm{F}_{3,83}=0.12, \mathrm{P}=0.95$; cinereous vulture: $F_{3,83}=0.71, P=0.55$, Figure 2) except for the griffon vulture, for which significant differences were found $\left(\mathrm{F}_{3,83}=\right.$ 117.54, $P=0.0001)$. The model predicted differences in the groups formed with $50 \%$ and $100 \%$ of domestic carcasses available 
Gypaetus barbatus
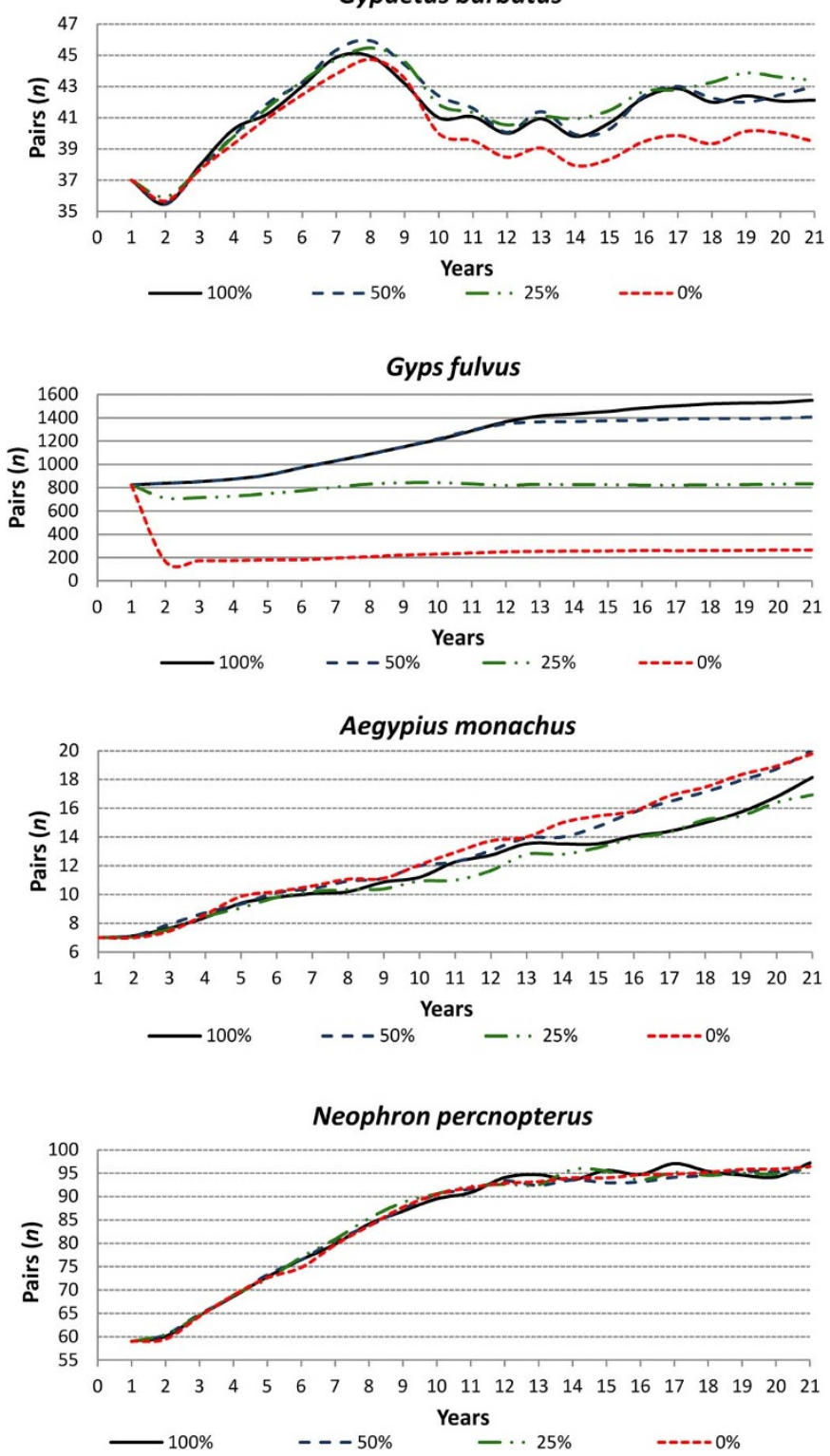

Figure $2 \mid$ Predicted population trends for the four avian scavengers in the study area, for each of the four scenarios tested, expressed as the percentage of domestic ungulate carcasses available in the ecosystem. Note the different $y$-axis scales.

compared to the $25 \%$ and $0 \%$ scenarios (Duncan's test, $\mathrm{P}<0.05$ ). With a quarter of domestic carcasses available, a $14 \%$ reduction in the griffon vulture population was forecast during the first year, after which their numbers were expected to become stable. In contrast, without domestic carcasses ( $0 \%$ scenario) a sudden decrease is expected with a reduction of $80 \%$ in griffon vulture populations, stabilizing at around 200-250 pairs. However, no global differences were found between $100 \%$ and $50 \%$ domestic carcass availability $(\mathrm{P}$ $=0.44)$, although the model indicated that statistically significant differences would be detected after the 12 th year $\left(\mathrm{F}_{1,268}=603.60, \mathrm{P}\right.$ $<0.0001)$ when there would be a reduction in the population growth of griffon vultures.

Assuming the network movements estimated in the study area (Figure 3), the predicted response of griffon vulture populations to the different scenarios studied is shown in Figure 4 . With $25 \%$ or $0 \%$ of domestic carcasses available, a significant reduction of the population was forecasted in all study areas. The decrease was especially important in populated areas (AR, PJ and AU). A decrease of $50 \%$ in the contributions of domestic carcasses was predicted to promote movement of animals between neighbouring areas (Figure 3). It was predicted that most individuals would not colonize new areas, so the population balance of the species in each area was not predicted to be affected (a trend similar to the $100 \%$ scenario) and only some individuals could colonize unoccupied areas such as VA and $\mathrm{C}$. The growth trend with $50 \%$ domestic carcass availability is similar to $100 \%$ availability during the first 12 years. After this time, the food resources in the receiving areas (VA, C, B and N) were predicted to be insufficient for all pairs such that there is a significant decrease in griffon vulture populations in areas $\mathrm{AR}, \mathrm{PJ}$ and $\mathrm{AU}$ and population stability only occurred with an increase in the biomass provided by wild ungulate populations.

Benefits of vulture ecological services. On average, the Spanish vulture populations were estimated to remove 133.6-200.5 $\mathrm{t}$ of bones and $5,550.7-8,326$ t of meat each year. The corresponding economic savings of natural carrion removal were estimated at a minimum of 907,679$1,488,719$ EUR, while vulture populations throughout the entire European Union may contribute an annual cost reduction of 972,915$1,595,715$ EUR. The animal biomass consumed by avian scavengers and removed from the ecosystem in the study area (assuming $50-75 \%$ of the diet is based on domestic ungulates) was estimated at $4.23-6.38 \mathrm{t}$ of bones and 176.73-265.10 $t$ of meat. This constituted annual benefits estimated at 28,900-47,400 EUR for farmers and authorities.

\section{Discussion}

Sudden changes in the availability of food may cause changes in the population dynamics of species ${ }^{26}$. The current study highlights the consequences of different levels of food availability on the population dynamics of an avian scavenger guild, indicating the halt and subsequent decline in population growth of the most meat-dependent species, i.e., the griffon vulture. The model predicted meat biomass to be the major limiting factor whereas the dietary plasticity of the other species allowed them to avoid declining population trends, as did their specific dietary habits (small animals for the Egyptian vulture and bones for the bearded vulture) and low densities. From a conservation perspective, these results suggest that the population growth of the most endangered species (Egyptian, cinereous, and bearded vultures) will continue in the current scenario, despite sanitary legislation that limits food resources ${ }^{13,16}$, given that a quarter of domestic ungulates are available in the ecosystem. However, this trend may be reversed by an increased effect of non-natural mortality when considering the effects of factors, such as illegal poisoning or lead poisoning, on breeding success and survival ${ }^{27-31}$. These problems currently affect the threatened bearded vulture and they appear to have stabilised their populations via non-natural mortality effects on adult survival ${ }^{29}$. In addition, given the difficult nature of assessing the numbers and age structure of the non-breeding population for modelling demographic trends and movements, and because these individuals mainly feed at supplementary feeding sites ${ }^{32}$, our model only considered the immature population (chicks reared). Thus, we can consider our model conservative because a portion of available food could benefit other non-breeding individuals.

In recent years, the Spanish griffon vulture population has experienced decreases in their breeding parameters and changes in the spatial distribution of the breeding and non-breeding population, while there have also been increases in their number of aggressive interactions with live livestock and an increase in the mortality of their young ${ }^{18,33}$. By contrast, other species have increased their populations, although illegal poisoning has affected some subpopulations ${ }^{27,30}$. It is speculated that these changes were due to food shortages, although no empirical evidence is presented to support this hypothesis. For the first time, the current study suggests that food limitations mainly affect griffon vultures. According to the model, vultures might respond to food shortages by shifting their spatial distribution leading to population decline (in the case of the $0 \%$ and $25 \%$ 
a)

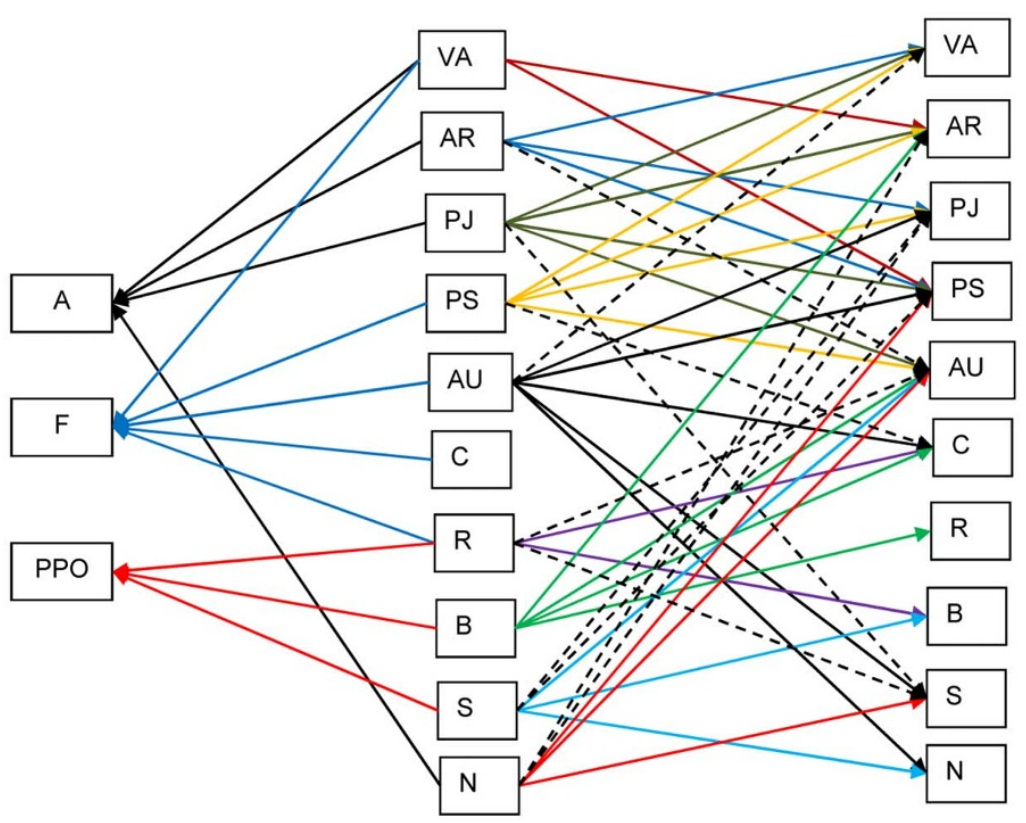

b)

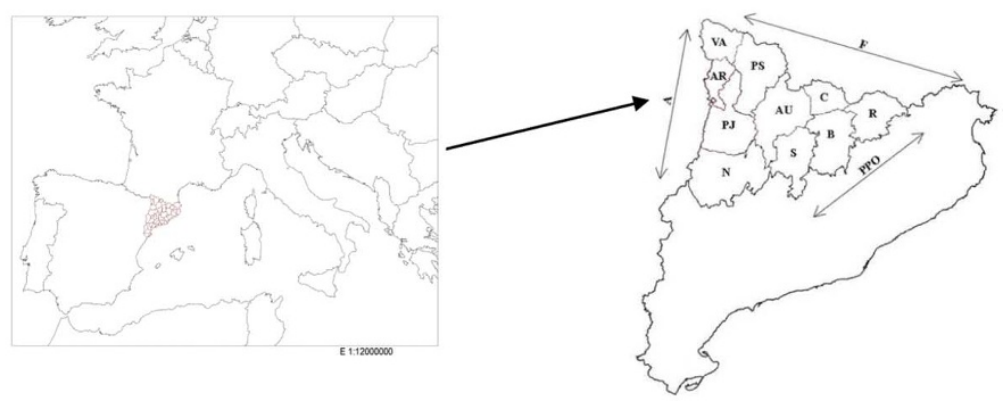

Figure $3 \mid$ (a) Possible avian scavenger foraging movements between areas, when there is a lack ofresources. The continuous lines are the possible movements of the bearded vulture (Gypaetus barbatus), Egyptian vulture (Neophron percnopterus), and cinereous vulture (Aegypius monachus). The dashed line represents the Eurasian griffon vulture (Gyps fulvus). (b) Distribution of the ten areas considered in the study: VA: Val d'Aran; AR:Alta Ribagorça; PJ: Pallars Jussà; PS: Pallars Sobirà; AU: Alt Urgell; C: Cerdanya; R: Ripollès; B: Berguedà; S: Solsonès; N: Noguera. A, F, and PPO correspond to peripheral areas (alternative environments in the model) in which the population might obtain alternative food resources outside of the study area (see more details in Methods).

scenarios) and these effects could accelerate in coming years if food limitations continue. These regressive scenarios suggested by the model do not imply an increase in mortality. Instead, individuals were predicted to abandon the ecosystem to search for suitable alternative areas where food and breeding sites are available, when food resources are insufficient and the carrying capacity at small spatial scales approaches the maximum levels. From an ecological perspective, griffon vultures are the dominant species of the avian scavenger guild in a competitive scenario because they can monopolise resources to the detriment of other species ${ }^{14}$. This suggests that the provision of supplementary feeding sites as a stopgap measure to meet food deficits would mainly favour this species. However, other ecological effects on the ecosystem of a population decline are unknown and the consequences may be a new concern for managers and policy-makers ${ }^{34}$. The ecological services provided by vultures have an important role and the regular use of feeding stations by these species could reduce ecological service provision in terms of scavenging ${ }^{18,25,35}$. In addition, the role of griffon vultures as facilitator species preparing carrion for other facultative and obligate scavengers is unknown but may have cascade effects within the ecosystem.

A more advisable management measure would be to reduce the amount of food provided at large feeding stations and promote the creation of smaller sites that simulate a trophic scenario by more closely resembling actual ecosystems, thereby preventing behavioural changes or any negative effects on population dynamics ${ }^{19,34,36,37}$. Based on the carrying capacity and the population trend observed, supplementary feeding programs appear to be unnecessary in hypothetical scenarios where half and $100 \%$ of domestic carcasses are available. The latter scenario corresponds to that present in the period before the establishment of sanitary regulations (progressively applied since 2006), which could be representative of most Mediterranean populations that are characterised by widespread grazing and the food resources provided by wild ungulates ${ }^{19,38}$. Thus, this study should be taken into account by managers and conservationists if the sanitary legislation is amended in the future. In fact, the presence of carcasses in the field as a consequence of extensive grazing is considered to be the most useful and economic method of managing avian scavenger populations ${ }^{13,17}$. This is an important issue for managers and policy-makers because solutions to the management of European vulture populations are based on an assumption that food shortages due to sanitary regulations should be compensated for with supplementary feeding sites. This management approach may have detrimental consequences because a patchy distribution of resources can artificially modify the habitat quality, with subsequent negative effects on population dynamics ${ }^{36,39}$. Thus, the carrying capacity should be regulated by feeding resources provided in the 

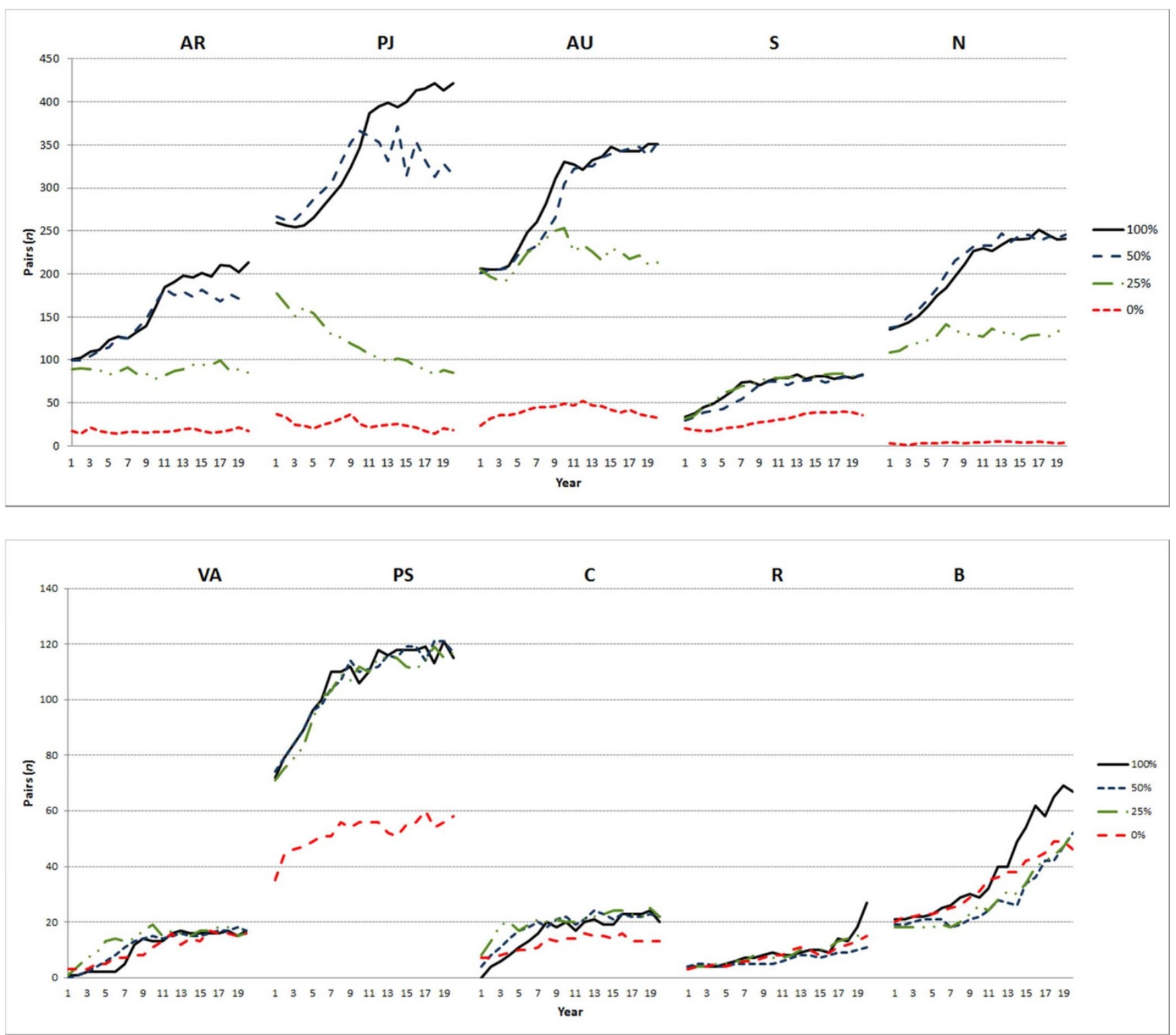

Figure $4 \mid$ Predicted population trend of the Eurasian griffon vulture in the different areas, according the four scenarios of domestic carcasses available. The population increase in several areas in which the species is initially absent (VA and C) or of low densities is a consequence of spatial changes related with food shortages or maximum carrying capacity.

ecosystem despite the long tradition in several countries of artificial food handling via supplementary feeding $\operatorname{sites}^{18}$. However, the sensitivity of some species (several threatened) in terms of demographic parameters, such as adult survival ${ }^{29,40,41}$ due to the presence of nonnatural mortality factors (mainly illegal poisoning ${ }^{42}$, could increase mortality rates and destabilise populations. Given that supplementary feeding increases pre-adult survival ${ }^{28}$, this method may continue to favour the most endangered species, especially if the quantity supplied is reduced and its unpredictability is increased.

The results of this study are relevant to future reintroduction and conservation projects. Our model is capable of identifying the spatial and temporal distribution of feeding resources, thereby facilitating the planning and optimisation of the most appropriate management approach, including supplementary feeding activities, to support the most food-poor areas where necessary. The application of this model to reintroduction projects demonstrates that calculations of food availability can provide guidelines when establishing the carrying capacity to optimise economic investment. In the case of avian scavengers, food availability studies can identify problems prior to reintroduction projects, thereby allowing managers to improve the success rate of reintroductions. This is particularly important for avian scavengers because they are highly dependent on carrion resources, the availability of which can be modified by humans by direct management, e.g., hunting of wild ungulates, the sanitary legislation for domestic ungulates, or the establishment of a network of supplementary feeding sites. Given the global decline affecting Old World vultures ${ }^{8}$, the availability of robust tools can help managers to optimise the investment of economic resources ${ }^{43,44}$ and to identify the most appropriate conservation measures.

\section{Methods}

Model building and assumptions. Using a Population Dynamic P System (see Supplementary Information) we defined a model allowing the study of the ecosystem dynamics in a zone subdivided into 10 areas inhabited by four avian scavengers whose diet depends on the food provided by the carcasses of wild and domestic ungulates. For the validation of the model ${ }^{19,24}$, we used census data obtained in the study area between 1994 and $2008^{24,25}$ taking into account the inter-annual variation in demographic parameters and density-dependent effects affecting the population trends observed. 
Besides natural and non-natural mortality, the model assumes that an ungulate

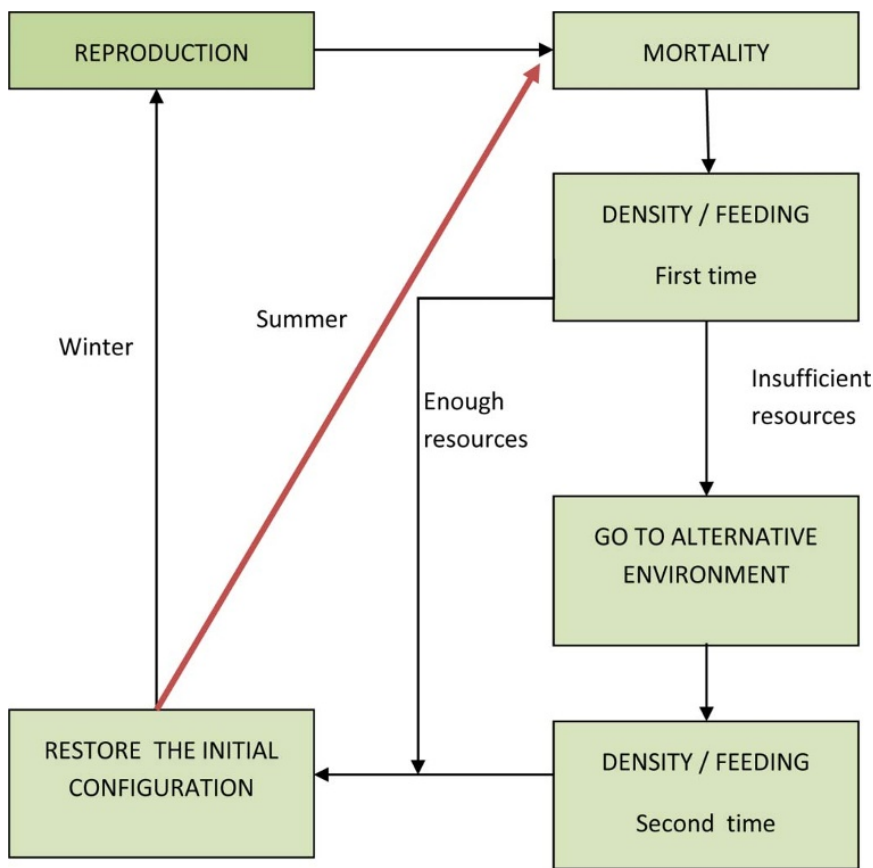

Figure $5 \mid$ Scheme of the model. The model takes into account two periods (summer and winter) and the basic processes of reproduction, mortality, and feeding. The scavenger birds forage in others areas when insufficient resources are available (i.e., they move). If food is scarce, the animals take the food and return to their initial area. They change territory if space is scarce. The carrying capacity of each area is limited and it is necessary to control the number of animals present. Before repeating the loop, it is necessary to restore the initial configuration. Two executions of a loop are equivalent to the passage of one year in the ecosystem.

The model consists of a loop with six modules (Figure 5). One year in the ecosystem involves running the loop twice, i.e., once for the summer period (four months) and once for the winter season (eight months). The model starts with the run of the reproduction module. The species are modelled with only one reproductive period each year. While the population of wild animals is a dynamic system conditioned by environmental and ecological factors, domestic animals are controlled by humans such that there are significant fluctuations in the population between the summer and winter as a consequence of transhumant movements.

In the reproduction module, all breeding age females can reproduce successfully in a probabilistic way. After the application of reproduction rules, the mortality module is carried out; there are two possible causes of death, i.e., natural mortality (e.g., senescence or accidents) and non-natural mortality (e.g., hunting or illegal poisoning). In most ungulate species (except wild boar), hunting practices are focused on males, producing variations in the sex-ratio. The model takes into account temporal and sex-ratio mortality variations influencing population growth and the biomass provided. In the following module the model takes into account whether food and carrying capacity are sufficient in the environment occupied to maintain their presence.

For each vulture species we obtained parameters on breeding, demography and energetic requirements according to their metabolism ${ }^{46}$ (Supplementary Information Table S2), mortality and the biomass that dead wild ungulates provided in the field, separating bone and meat remains in accordance with the different dietary habits of the species ${ }^{19}$. The diet of avian scavengers is complemented by external inputs through supplementary feeding sites and in smaller quantities by other small species

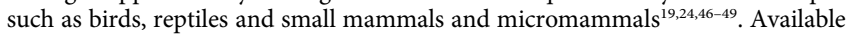
grass biomass is enough to cover the energetic requirements of wild and domestic ungulates $^{50,51}$ and has not been considered as a limiting factor.

With respect to the interspecific hierarchies in the access and exploitation of carrion, we consider that Egyptian and cinereous vultures are the first species to access the carrion and griffon and bearded vultures the last (A.M. unpubl. data). Intraspecific age hierarchies are not differentiated in access to food, since the behavioral patterns observed at feeding sites ${ }^{52-54}$ may differ from the random distribution of food in the wild.

When resources are limited, they are distributed randomly according to the number of individuals of each species competing for the same type of food and according to the amount of resources they need. The model also takes into account the presence of a non-breeding population (Table S2) consisting of fledglings produced by the breeding population. These are counted individually and when they reach breeding maturity, two individuals become a breeding pair occupying a new territory. dies when it lacks physical space as a consequence of its carrying capacity. In the case of avian scavengers, if a species has insufficient resources it moves to nearby areas. It returns to the starting point if there are food limitations but no space limitations. An individual colonises a new area if insufficient space is available. Scavengers can choose from more than one destination if they need to move, and they select one randomly. If the alternative area selected lacks resources, this random sampling continues until resources are found, leaving the ecosystem if resources are not found.

If there is an avian scavenger who lacks sufficient resources after carrying out the rules of feeding and controlling for the maximum density of each species, it will move to another environment, running the feeding process and/or density previously unrealized for this animal. If space is not a limiting factor, they will return to the source environment or otherwise colonize a new area.

When defining the model, a directed network-graph of avian scavenger movement is specified (Figure 3). The avian scavengers move to search for food in the peripheral areas (A, F, PPO) when feeding resources in the regular home ranges are insufficient. For the foraging areas, we consider the maximum linear foraging movement from the nest for the griffon vulture to be $90 \mathrm{~km}, 40 \mathrm{~km}$ for the bearded vulture, $15 \mathrm{~km}$ for the Egyptian vulture and $60 \mathrm{~km}$ for the cinereous vulture ${ }^{46}$ (A.M. unpubl. data). The model takes into account that each species takes advantage of the resources close to their nesting area and widens the radius of their movements as they deplete. The amount of meat and bones consumed by scavengers depends on the season. The excess meat disappears from the ecosystem at the end of each period (summer or winter). The model assumes that $20 \%$ of the unconsumed bones remain available in the ecosystem, because bones can be preserved for up to 10 times longer than meat ${ }^{55}$. Populations of animals will generally grow exponentially if they have sufficient resources, although this growth is restricted due to limitations in physical space, which supports the maximum carrying capacity used in the model (Table S1). The objective of the final module is to restore the initial configuration to restart the loop. Running the model requires some initial parameters, so these are entered before returning an output. The evolution rules used by the model are run for each individual and they are executed simultaneously for all individuals. Thus, the system operates in parallel, which means there can be competition when animals of the same or different species share resources. The values of the parameters used in the model were derived from the bibliography ${ }^{19,24}$. The running model is detailed in Supplementary Information.

Management scenarios. Several possible scenarios were modelled by testing the impact of different food availability regimes to elucidate their potential effects on population projections over time. Four initial scenarios were considered that depended on the hypothetical biomass provided by domestic ungulates. Thus, the $100 \%$ scenario represented the ecosystem function prior to the application of sanitary regulations ${ }^{13,16}$ where all domestic and wild ungulate carcasses were available to the avian scavenger guild. The $50 \%$ scenario represented a scenario where only half of the hypothetical food resources provided by domestic carcasses were available. The $25 \%$ scenario might reflect a scenario that is similar to the current situation because approximately $80 \%$ of carcasses are recovered and destroyed by specialist companies. Finally, the $0 \%$ scenario simulates an ecosystem where food is provided only by wild ungulates.

First, the biomass was calculated provided for each subzone by subtracting the megacalories available from the energetic requirements of the avian scavengers inhabiting each subzone. This provided a picture of the surplus or constraints on food availability from a spatial perspective. Second, the population trend was simulated with consideration for the demographic parameters of hypothetical growth in each species (see Supplementary Information) and the availability of biomass provided by the different scenarios plus the biomass provided by wild ungulates and feeding stations. Data used for the a posteriori statistical analyses were obtained by using the model to simulate the population dynamics (21 years and a total of 50 replicates) in a probabilistic manner, which reflected the random behaviour of the natural situation.

Quantifying carrion removal vs. vulture ecological services. To estimate the potential biomass that avian scavengers can remove from the ecosystem, the annual energetic requirements of each individual and species were determined based on their standard metabolism ${ }^{48,56,57}$, and then multiplied by the number of individuals present in the ecosystem. It was estimated that $50-75 \%$ of the diet of avian scavengers was composed of domestic ungulate remains, which was based on the animal biomass range (its natural removal from the ecosystem). To compare the results, this estimate of the ecological services provided by the Spanish vulture population was added to the total for the European population ${ }^{16}$. The cost of removing this carrion for farmers and authorities was calculated as the cost for the removal and transport of each ton of carrion: an average of $89 \mathrm{EUR}$, and the cost of disposal in authorised plants, 76.3 EUR $^{58}$. This allowed the economic estimate of the ecological services performed by avian scavengers to be compared with the cost of carrion removal.

Statistical analyses. Normality of the data was confirmed using the KolmogorovSmirnov test, before a one-way ANOVA to compare the annual population trend of avian scavengers obtained in different management scenarios. This analysis took into account the animal biomass as a dependent variable while the species were factors. When ANOVA tests were significant, a further test of homogeneity was performed using Duncan's test to identify inter-group differences.

1. Loreau, M., Naeem, S. \& Inchausti, P. Biodiversity and ecosystem functioning: synthesis and perspectives, Oxford University Press, 2002. 
2. Loreau, M. Linking biodiversity and ecosystems: towards a unifying ecological theory. Philos. Trans. R. Soc. B 36, 49-60 (2010).

3. Naeem, S. et al. Biodiversity, ecosystem functioning and human wellbeing: an ecological and economic perspective, Oxford University Press, 2009.

4. Sekercioglu, C. H., Daily, G. C. \& Ehrlich, P. R. Ecoystem consequences of bird declines. Proc. Ntl. Acad. Sci. USA 101, 18042-18047 (2004).

5. Whelan, C. J., Wenny, D. G. \& Marquis, R. J. Ecosystem services provided by birds. Ann. New York Acad. Sci. 1134, 25-60 (2008).

6. Wenny, D. G. et al. The need to quantify ecosystem services provided by birds. Auk 128, 1-14 (2011).

7. DeVault, T. L., Rhodes, O. E. \& Shivik, J. A. Scavenging by vertebrates: behavioral, ecological, and evolutionary perspectives on an important energy transfer pathway in terrestrial ecosystems. Oikos 102, 225-234 (2003).

8. Oaks, L. et al. Diclofenac residues as the cause of vulture population declines in Pakistan. Nature 427, 630-633 (2004).

9. Green, R. E. et al. Diclofenac poisoning as a cause of vulture population declines across the Indian subcontinent. J. Appl. Ecol. 41, 793-800 (2004).

10. Thiollay, J. M. Raptor declines in West Africa: comparisons between protected, buffer and cultivated areas. Oryx 41, 322-329 (2007).

11. Naidoo, V., Wolker, K., Cuthbert, R. \& Duncan, N. Veterinary diclofenac threatens Africa's endangered vulture species. Regul. Toxicol. Pharm. 53, 205-208 (2009).

12. Virani, M. Z., Kendall, C., Njoroge, P. \& Thomsett, S. Major declines in the abundance of vultures and other scavenging raptors in and around the Masai Mara ecosystem, Kenya. Biol. Conserv. 144, 746-752 (2011).

13. Donázar, J. A., Margalida, A., Carrete, M. \& Sánchez-Zapata, J. A. Too sanitary for vultures. Science 326, 664 (2009).

14. Cortés-Avizanda, A., Carrete, M. \& Donázar, J. A. Managing supplementary feeding for avian scavengers: guidelines for optimal design using ecological criteria. Biol. Conserv. 143, 1707-1715 (2010).

15. Tella, J. L. Action is needed now, or BSE crisis could wipe out endangered bird of prey. Nature 410, 408 (2001).

16. Margalida, A., Donázar, J. A., Carrete, M. \& Sánchez-Zapata, J. A. Sanitary versus environmental policies: fitting together two pieces of the puzzle of European vulture conservation. J. Appl. Ecol. 47, 931-935 (2010).

17. Margalida, A., Carrete, M., Sánchez-Zapata, J. A. \& Donázar, J. A. Good news for European vultures. Science 335, 284 (2012).

18. Donázar, J. A, Margalida, A. \& Campión, D. Vultures, feeding stations and sanitary legislation: a conflict and its consequences from the perspective of conservation biology. Sociedad de Ciencias Aranzadi 2009.

19. Margalida, A., Colomer, M. A. \& Sanuy, D. Can wild ungulate carcasses provide enough biomass to maintain avian scavenger populations? An empirical assessment using a bio-inspired computational model. PLoS One 6, e20248 (2011).

20. Bousquet, F. C. \& Le Page, C. Multi-agent simulations and ecosystem management: a review. Ecol. Model. 176, 313-332 (2004).

21. Păun, G. Computing with membranes. J. Comp. Syst. Sci. 61, 108-143 (1998).

22. Păun, G., Rozenberg, G. \& Salomaa, A. The Oxford Handbook of Membrane Computing, Oxford University Press, 2010.

23. Cardona, M. et al. Modelling ecosystems using P Systems: The Bearded Vulture, a case study. Lect. Notes Comput. Sc. 5391, 137-156 (2009).

24. Colomer, M. A., Margalida, A., Sanuy, D. \& Pérez-Jiménez, M. J. A bio-inspired computing model as a new tool for modeling ecosystems: the avian scavengers as a case study. Ecol. Model. 222, 33-47 (2011).

25. Dupont, H., Mihoub, J. B., Becu, N. \& Sarrazin, F. Modelling interactions between scavenger behaviour and farming practices: Impacts on scavenger population and ecosystem service efficiency. Ecol. Model. 222, 982-992 (2011).

26. Ostfeld, R. S. \& Keesing, F. Pulsed resources and community dynamics of consumers in terrestrial ecosystems. Trends Ecol. Evol. 15, 232-237 (2000).

27. Hernández, M. \& Margalida, A. Pesticide abuse in Europe: effects on the Cinereous vulture (Aegypius monachus) population in Spain. Ecotoxicology 7, 264-272 (2008).

28. Gangoso, L. et al. Long-term effects of lead poisoning on bone mineralization in vultures exposed to ammunition sources. Environ. Pollut. 157, 569-574 (2009).

29. Oro, D. et al. Testing the goodness of supplementary feeding to enhance population viability in an endangered vulture. PLoS One 3, e4084 (2008).

30. Hernández, M. \& Margalida, A. Poison-related mortality effects in the endangered Egyptian Vulture (Neophron percnopterus) population in Spain: conservation measures. Eur. J. Wildl. Res. 55, 415-423 (2009).

31. Hernández, M. \& Margalida, A. Assessing the risk of lead exposure for the conservation of the endangered Pyrenean bearded vulture (Gypaetus barbatus) population. Environ. Res. 109, 837-842 (2009).

32. Margalida, A., Oro, D., Cortés-Avizanda, A., Heredia, R. \& Donázar, J. A. Misleading population estimates: biases and consistency of visual surveys and matrix modelling in the endangered Bearded Vulture. PLoS One 6, e26784 (2011).

33. Margalida, A., Campión, D. \& Donázar, J. A. European vultures' altered behaviour. Nature 480, 457 (2011).

34. Olson, Z. J., Beasley, J. C., DeVault, T. L. \& Rhodes, E. jr. Scavenger community response to the removal of a dominant scavenger. Oikos 121, 77-84 (2011).

35. Deygout, C., Sarrazin, F., Gault, A. \& Bessa-Gomes, C. Modeling the impact of feeding stations on vulture scavenging service efficiency. Ecol. Model. 220 1826-1835 (2009).

36. Carrete, M., Donázar, J. A. \& Margalida, A. Density-dependent productivity depression in Pyrenean Bearded Vultures: implications for conservation. Ecol.Appl. 16, 1674-1682 (2006).
37. Dupont, H, Mihoub, J. B., Bobbe, S. \& Sarrazin, F. Modelling the consequences of farmer's carcass disposal practices on scavengers' ecological service. J. Appl. Ecol. 49, 404-411 (2012).

38. Olea, P. \& Mateo-Tomás, P. The role of traditional farming practices in ecosystem conservation: the case of transhumance and vultures. Biol. Conserv. 142, 1844-1853 (2009)

39. Robb, G. N., McDonald, R. A., Chamberlain, D. E. \& Bearhop, S. Food for thought: supplementary feeding as a driver of ecological change in avian populations. Front. Ecol. Environ. 6, 476-484 (2008).

40. Le Gouar, P. et al. Roles of survival and dispersal in reintroduction success of Griffon vulture (Gyps fulvus). Ecol. Appl. 18, 859-872 (2008).

41. Grande, J. M. et al. Survival in a long-lived territorial migrant: effects of life-history traits and ecological conditions in wintering and breeding areas. Oikos 118, 580-590 (2009).

42. Margalida, A. Poison baits and funding cuts: a deadly mix. Science (In press).

43. Sutherland, W. J. \& Freckleton, R. P. Making predictive ecology more relevant to policy makers and practitioners. Philos. Trans.R. Soc. B 367, 322-330 (2012)

44. Wilson, H. B., Joseph, L. N., Moore, A. L. \& Possingham, H. P. When should we save the most endangered species? Ecol. Lett. 14, 886-890 (2011).

45. Cardona, M. et al. A P-System based model of an ecosystem of some scavenger birds. Lect. Notes Comput. Sc. 5957, 182-195 (2010).

46. Donázar, J. A. The Iberian Vultures. Biology and Conservation, J.M. Reyero Editor, 1993.

47. Margalida, A., Bertran, J. \& Heredia, R. Diet and food preferences of the endangered Bearded vulture Gypaetus barbatus: a basis for their conservation. Ibis 151, 235-243 (2009)

48. Margalida, A. et al. Long-term relationship between diet and breeding success in a declining population of Egyptian Vulture. Neophron percnopterus Ibis 154, 184-188 (2012)

49. Donázar, J. A., Cortés-Avizanda, A. \& Carrete, M. Dietary shifts in two vultures after the demise of supplementary feeding stations: consequences of the EU sanitary legislation. Eur.J. Wildl. Res. 56, 613-621 (2010).

50. Fillat, F. Gestión semi-extensiva de prados y pastos europeos ricos en especies: caso particular de los Pirineos españoles. Pastos 33, 171-215 (2006).

51. García-Martínez, A., Olaizola, A. \& Bermués, A. Trajectories of evolution and drivers of change in European mountain cattle farming systems. Animal 3 152-165 (2009).

52. Bosè, M. \& Sarrazin, F. Competitive behaviour and feeding rate in a reintroduced population of Griffon Vultures . Gyps fulvus Ibis 149, 490-501 (2007).

53. Bosè, M., Duriez, O. \& Sarrazin F. 2012 Intra-specific competition in foraging griffon vultures: 1. The dynamics of feeding in groups. Bird Study 59, 182-192 (2012).

54. Duriez, O., Herman, S. \& Sarrazin, F. 2012 Intra-specific competition in foraging griffon vultures: 2 . the influence of supplementary feeding management. Bird Study 59, 193-206 (2012).

55. Houston, D. C. \& Copsey, J. A. Bone digestion and intestinal morphology of the Bearded Vulture. J. Raptor Res. 28, 73-78 (1994).

56. Prinzinger et al. Energy metabolism and body temperature in the Griffon Vulture (Gyps fulvus) with comparative data on the Hooded Vulture (Necrosyrtes monachus) and the White-backed Vulture (Gyps africanus). J. Ornithol.143, 456-467, (2002)

57. King, J. R. \& Farner, D. S. Energy metabolism, thermoregulation and body temperature. In, Marshall, J. A. (Ed.) Biology and comparative physiology of birds Vol. II New York: Academic Press, pp. 215-288, 1961.

58. Boumellasa, H. Rapaces nécrophages: concilier conservation de l'espèce et minimisation des dépenses, vers un reinforcement du lien AgricultureEnvironment. University Paris X 2004.

\section{Acknowledgements}

We gratefully acknowledge the Natural Computing Group at Sevilla University for their help with the design of the simulator. AM was supported by the Departament d'Agricultura Ramaderia, Pesca i Medi Natural of Generalitat de Catalunya and Ministerio de Medio Ambiente.

\section{Author contributions}

A.M. and M.A.C. designed the experiment, collected all the data, performed analysis of the data, and wrote the manuscript. Both the authors discussed the results and commented on the manuscript.

\section{Additional information}

Supplementary information accompanies this paper at http://www.nature.com/ scientificreports

Competing financial interests: The authors declare no competing financial interests.

License: This work is licensed under a Creative Common

Attribution-NonCommercial-NoDerivative Works 3.0 Unported License. To view a copy of this license, visit http://creativecommons.org/licenses/by-nc-nd/3.0/

How to cite this article: Margalida, A. \& Colomer, M. ̀. Modelling the effects of sanitary policies on European vulture conservation. Sci. Rep. 2, 753; DOI:10.1038/srep00753 (2012) 